\title{
GIS SUPPORTING SURVEYS FOR URBAN SUSTAINABILITY ASSESSMENT
}

\author{
Nicola Moretti ${ }^{1}$, Sebastiano Maltese ${ }^{2}$, Mario Claudio Dejaco ${ }^{3}$, Fulvio Re Cecconi ${ }^{4}$
}

\begin{abstract}
Urban Facility Management (UFM) is an effective framework to support management of the complexity of the city environment, to optimise resources, enhance quality and guarantee citizen's safety. Nevertheless, it can be observed a lack of standardised objective tools for urban quality assessment of existing neighbourhoods. In this paper, a procedure for urban sustainability assessment exploiting Geographic Information Systems (GIS), Database Management Systems (DBMS) and mobile devices is presented. A system called District Information Model (DIM) is employed for this purpose, in order to detect the anomalies and enable evaluation of urban components' average conservation status. The results of the survey supported the implementation of an UFM service in an Italian Neighbourhood, near Milan.

UFM can be intended as a framework to pursuit urban sustainability objectives, in the wider context of Europe 2020 strategy. Thus, the process leading to urban sustainability reporting through the DIM has been investigated, through a case study research. In conclusion, the system can be seen as a risk prevention tool both for citizens and professionals working for management of built environment; and as a sustainability assessment tool compliant with most recognised Neighbourhood Sustainability Assessment (NSA) protocols.
\end{abstract}

Keywords: urban facility management, information modelling, neighbourhood sustainability assessment, district survey and management.

\section{INTRODUCTION}

Dealing with management of the urban environment, the first issue to be considered is complexity. The city can be seen as a condensation and stratification of tangible and intangible phenomena (artificial and natural elements, culture, habits etc.), which constitute the environment where people live. Therefore, an adequate quality level of the built environment must be granted, through the development of innovative and effective tools and practices.

Urban Facility Management (UFM), namely the integrated management of services supporting operation, fruition and valorisation of urban goods (UNI 11447, 2012), assumes key role. Moreover, UFM in the wider context of Europe 2020 strategy, may be considered as a framework to achieve a higher level of sustainability for the urban environment. Social progress, environmental protection, economic welfare and

\footnotetext{
${ }^{1} \mathrm{PhD}$ Candidate at Department of Architecture, Built Environment and Construction Engineering, Politecnico di Milano, via G. Ponzio, 31 - 20133 Milano (MI) - Italy, nicola.moretti@polimi.it

${ }^{2}$ Research fellow at Department of Architecture, Built Environment and Construction Engineering, Politecnico di Milano, via G. Ponzio, 31 - 20133 Milano (MI) - Italy, sebastiano.maltese@polimi.it

${ }^{3}$ Assistant professor at Department of Architecture, Built Environment and Construction Engineering, Politecnico di Milano, via G. Ponzio, 31 - 20133 Milano (MI) - Italy, mario.dejaco@polimi.it

${ }^{4}$ Associate professor at Department of Architecture, Built Environment and Construction Engineering, Politecnico di Milano, via G. Ponzio, 31 - 20133 Milano (MI) - Italy, fulvio.rececconi@polimi.it
} 
institutional commitment in our cities are defined as the four dimensions of sustainability (Sharifi and Murayama, 2015). Accordingly, this paper presents a procedure, addressing the issue of management of two of those: social progress and environmental protection. Thus, attempting to pursuit an objective evaluation, a case study research concerning the assessment of the physical condition of urban elements in an Italian business district next to Milan, is presented. In this experience, a survey tool, developed exploiting the potentialities of a Database Management System (DBMS), together with a Geographical Information System (GIS) software, has been applied.

Altogether, concerning social progress, will be presented how the survey tool could support the evaluation of safety issues related to the urban environment, spotting the most critical precincts in the neighbourhood under analysis. For environmental protection, the integration in the tool of a Neighbourhood Sustainability Assessment (NSA) module leading to a sustainability rating report, is exploited.

The paper concludes with some considerations on drawbacks and next development of the research, suggesting a possible integration in a Building Information Modelling (BIM) process.

\section{STATE OF ART}

In the next paragraphs a brief state of the art on the topics faced during this research will be presented.

\subsection{Social sustainability assessment}

Social progress, as mentioned before, is one of the three pillars of sustainability concept. With respect to this topic and taking into account UFM perspective, one of the most significant issues to be considered in the survey phase is safety, both for users and technicians performing maintenance interventions. Safety issues increase the risk level of a given component that, according to UNI EN 15331 (2011), is one of the key parameters leading to emergency maintenance, namely the most critical and urgent. Glancing at the built environment, some interesting experiences, confirm the importance of safety issues related to the quality of neighbourhoods.

In Business Improvement Districts (BID), for instance (management structures born in the '60 for revitalising urban areas through a peculiar economical mechanism), achievement of a high safety level is crucial to attain their scope of enhancement of common urban spaces (Hoyt and Gopal-Agge, 2007). Moreover, looking at the Italian context, Milan municipality's building regulations, asserts that safety of urban environment has a primary importance for urban regeneration and maintenance (Comune di Milano, 2014).

The origin of safety issues can be identified in degradation phenomena not only related to the physical entities, but also to social aspects. Often these two characterisations are tied, and conditioned mutually. Italian CRESME research centre, for instance, identifies, among others, degradation of neighbourhoods' physical condition and scares road illumination as enabling factors for social degradation and safety perception of urban areas (Toso, 2003). Needless to say that urban maintenance can be seen, in this perspective, as a tool to tackle social and physical degradation.

\subsection{Environmental sustainability assessment}

During the last decade, a growing attention to urban sustainability rating protocols can be noticed (Yildiz et. al., 2016). The main focus of these last generation frameworks, 
namely the Neighbourhood Sustainability Assessment (NSA) tools, concerns specifically environmental sustainability of the neighbourhood as a whole. Nevertheless, few studies can be found in sustainability assessment of existing boroughs, since NSA tools are mostly oriented on evaluation of new development, rather than retrofitting and improvement processes.

Sustainability is a key issue to foster the neighbourhoods' quality (Komeily and Srinivasan, 2015), although its relevance varies according to stakeholders' perspective. For real estate players, better neighbourhoods' sustainability performances, may affect issues related to sale price, reducing costs of developments as well as increasing of marketing appeal are relevant factors. The latter aspect appears to be crucial also for designers and engineers, furthering their design decisions. Also public administrations can gather advantages from urban sustainability issues, enhancing consensus through a green policy conduct and establishing a dialogue with the private sector encouraging sustainable urban development practices (Sullivan et. al., 2014).

Some of the most common NSA tools are, for instance LEED Neighborhood Development (US), BREEAM Community (UK), DGNB NSQ/NUD (De), CASBEE UD (Ja) and Green Mark Districts (Aus) (Wangel et. al., 2016), (Yildiz et. al., 2016), (Yoon and Park, 2015), (Sharifi and Murayama, 2014). Despite being the list not comprehensive, to date, these are some of the most used worldwide. Nevertheless, the shifting of attention from buildings to neighbourhoods, keeping the attention to sustainability assessment, makes the field work fruitful, therefore new versions and protocols emerged in the last years. Borrowing an analogous rating and certification methodology from the building sustainability rating protocols, these tools assign a score to the urban environment's characteristics, according to the compliance with some quality requirements (Maltese et. al., 2016b). Despite the above mentioned tools can be considered a remarkable framework for evaluation of neighbourhoods, some drawbacks can be highlighted. The most relevant are mainly related to the development of the specific NSA tools, in a specific national context and to the massive attention given to evaluation of the construction process, instead of the actual environmental performance of the assessed settlement (Wangel et. al., 2016).

\section{A SURVEY TOOL FOR ENABLING ENVIRONMENTAL AND SOCIAL SUSTAINABILITY}

Thanks to the possibility offered by this tool to manage a great amount of information, a Geographical Information System (GIS) has been adopted as core engine for data processing, in the case study. GIS presents also advantages in terms of data storage management and interoperability, since semantic information can be stored in a spreadsheet, both human and machine readable. This information is then coupled with geometric one, to allow spatial analysis. GIS potentiality is enhanced through the combined use of a Database Management System (DBMS) which can be considered, in this case, as a sort of structured data warehouse, allowing organisation of data and queries. Exploitation of both these two instruments fosters UFM processes, while reducing uncertainty in the whole process (e.g. easing information flow). Accordingly, a modular information model has been setup: the so-called District Information Model (DIM). The DIM, presents a further particularity: the survey campaign phase is performed using portable devices (smartphone and tablet), on which has been installed a DBMS editor exploiting a Graphical User Interface (GUI) designed for the purpose. 
Therefore, timing for urban components' detection has been significantly reduced. The DIM has been applied, fostering the setup of a UFM service for Quartiere Affari in San Donato Milanese, Milan, Italy (Maltese et. al., 2016a). In this paper, the process to achieve social and environmental sustainability assessment is presented (Figure 1).

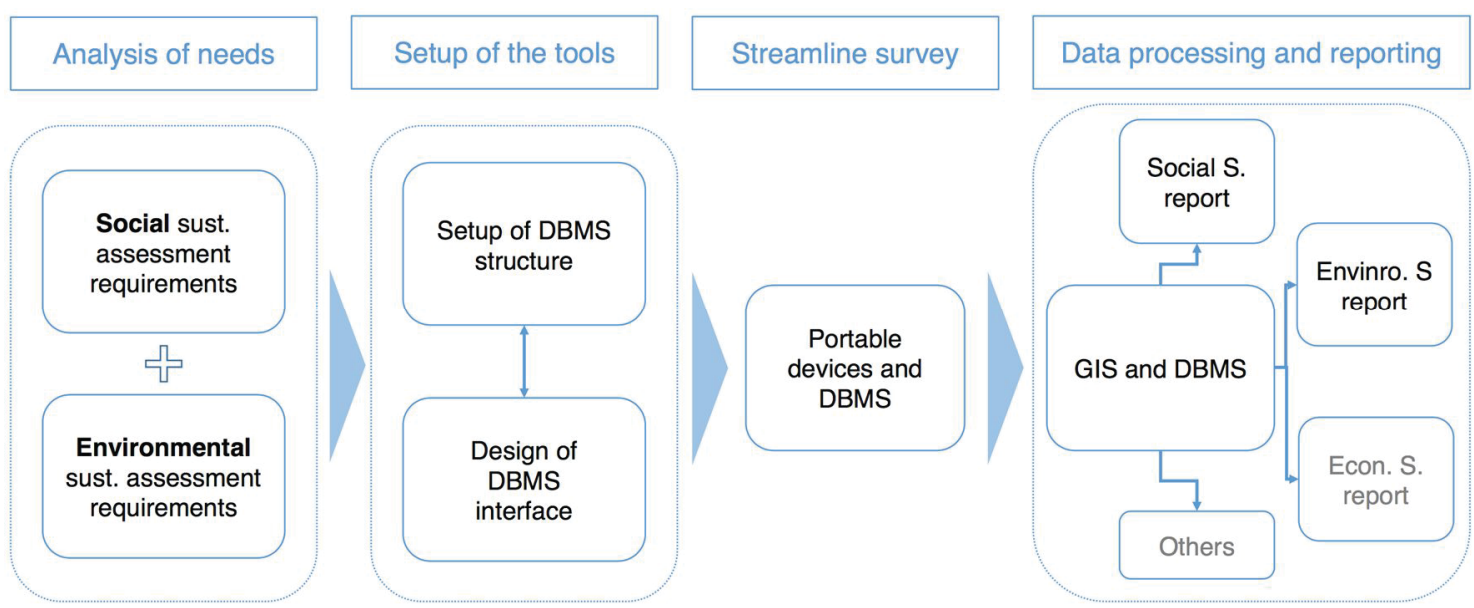

Figure 1: Scheme of the streamlined DIM procedure.

\subsection{District Information Model - DIM}

In the development of the model, first step was the definition of the information contents. The aim was to speed up the survey campaign and data analysis, thus a careful selection of information to be collected (in Table 1) has been done.

Table 1: Main categories of contents of the District Information Model.

\begin{tabular}{ll}
\hline Type of information & Information to be collected in the DIM \\
\hline Neighbourhood's registry & $\begin{array}{l}\text { Mainly concerning construction year, localization, } \\
\text { quantitative data about items, urban planning tools and } \\
\text { forecasts. }\end{array}$ \\
Population's registry & $\begin{array}{l}\text { Quantitative and qualitative information on population. } \\
\text { Physical elements' characteristics }\end{array}$ \\
Management and maintenance & $\begin{array}{l}\text { Breakdown of urban goods and urban elements } \\
\text { e.g. maintenance instruction (by the manufacturer), } \\
\text { instruction for proper removal and disposal, instruction } \\
\text { for functionality maintenance, health and safety } \\
\text { measures, maintenance interventions roll. }\end{array}$ \\
\hline
\end{tabular}

In Italy, similar attempt to manage technical information related to buildings can be found: the Libretto del Fabbricato or Fascicolo del Fabbricato (ANCE, 2014) (Dejaco et. al., 2017). However, the application of this framework it is not commonly implemented for urban environment assessment. Nevertheless, the exploitation of this consolidated approach in the urban environment, suggested the development of an effective workflow for streamlined surveys.

After the definition of the main contents of the DIM, the survey campaign was performed, as well as data storage and analysis. Table 2 summarises the most relevant steps. 
Table 2: Phases of the work.

\begin{tabular}{|c|c|c|c|}
\hline Stage & Activity & Stage & Activity \\
\hline \multirow[t]{3}{*}{ 1. Preliminary } & Analysis of documentation & 3. Survey & Scheduling of inspections \\
\hline & Interviews & & Execution of the survey \\
\hline & Preliminary survey & & Adjustments and corrections \\
\hline \multirow[t]{3}{*}{ 2. Design } & $\begin{array}{l}\text { Definition of registry } \\
\text { system }\end{array}$ & $\begin{array}{l}\text { 4. Data } \\
\text { processing }\end{array}$ & Data analysis \\
\hline & $\begin{array}{l}\text { Definition of level of } \\
\text { information }\end{array}$ & & Thematic reporting \\
\hline & $\begin{array}{l}\text { Preparation of the support } \\
\text { database }\end{array}$ & & \\
\hline
\end{tabular}

As mentioned before, filling the database, we adopted portable devices (e.g. smartphone or tablet). Therefore, all at once information (e.g. photographs characteristics and conditions of physical elements) was stored in the database. Accordingly, timing for surveys shortened remarkably: for detection of urban components in a linear road branch of $100 \mathrm{~m}$ were employed 2 people for an overall timing of $1 \mathrm{~h}$. As a whole, 297 survey forms has been filled in one week, for a total amount of 476 anomalies detected.

\subsection{District maintenance logbook reporting}

GIS software allowed to import information detected during the survey in thematic maps, exploited to define the level of degradation of some urban areas. Accordingly, Figure 2 shows concentration of anomalies in a radius of $20 \mathrm{~m}$.

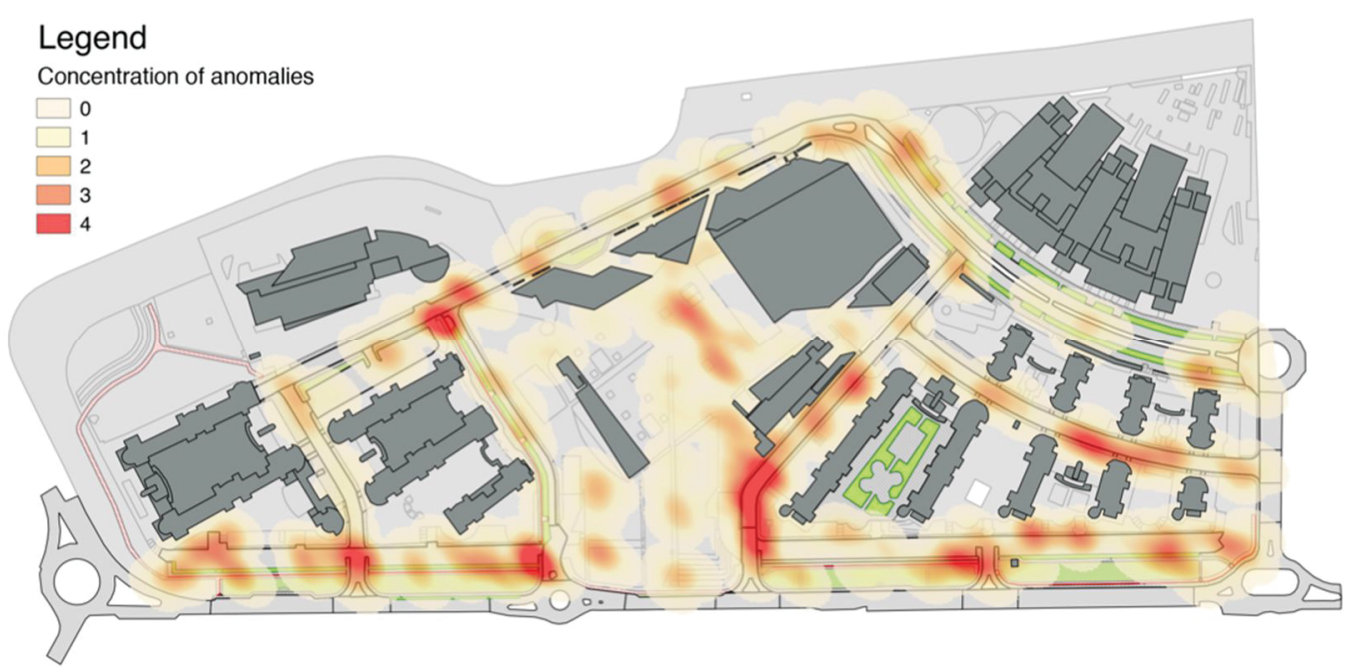

Figure 2: Example of failure concentration map (20m radius).

Despite being quite easy to identify safety issues for a single urban element, when the amount of information concerning the whole built environment become consistent, a prioritisation strategy to define a sequence of operation to be accomplished, should be defined. The map in Figure 2, has been employed for this purpose: red areas are precincts in which maintenance interventions must be performed first, therefore where social 
sustainability issues can be heavier, since priority of maintenance interventions has been taken as key indicator. One of the characteristics to be checked during the survey, was precisely the safety issue for users and technicians. So, considering results represented in the map, it can be stated that a higher level of urban components' degradation corresponds to a higher level of safety risk for people.

\subsection{Neighbourhood sustainability assessment reporting}

As presented in paragraph 2.2, NSA tools focus on environmental assessment of urban environment. Thus, BREEAM Communities rating protocol (BREEAM, 2012) was chosen, to carry out an environmental sustainability assessment through the DIM. The preference for BREEAM Com., has been expressed since it is the Western NSA tool that mostly focuses on environmental features. Moreover, being developed by UK Green Building Council, seems to be more suitable for assessment of European neighbourhoods (Wangel et. al., 2016). For this purpose, a demonstration concerning the $L E 04-$ Enhancement of ecological value criterion, is presented in Figure 3. It must be highlighted that most of the criterion's parameters to be calculated to obtain a maximum of 3 points are qualitative. On the other hand, some of them can be computed. In particular, we propose a methodology for assessment of parameters called amenities and social provisions, occupier/user health and wellbeing and aesthetic value of green spaces on and near to the site. Thus, in the map are represented anomalies detected on technological units, related to the parameters cited above. Through a concentration map, it is possible to depict the maintenance status of urban furniture and green areas: relevant indicators of quality of spaces. Moreover, this is not the only criterion which can be assessed through the DIM. LE 05 - Landscape, as instance, can be assessed following a similar procedure, despite the spatial analysis to be performed could vary slightly.

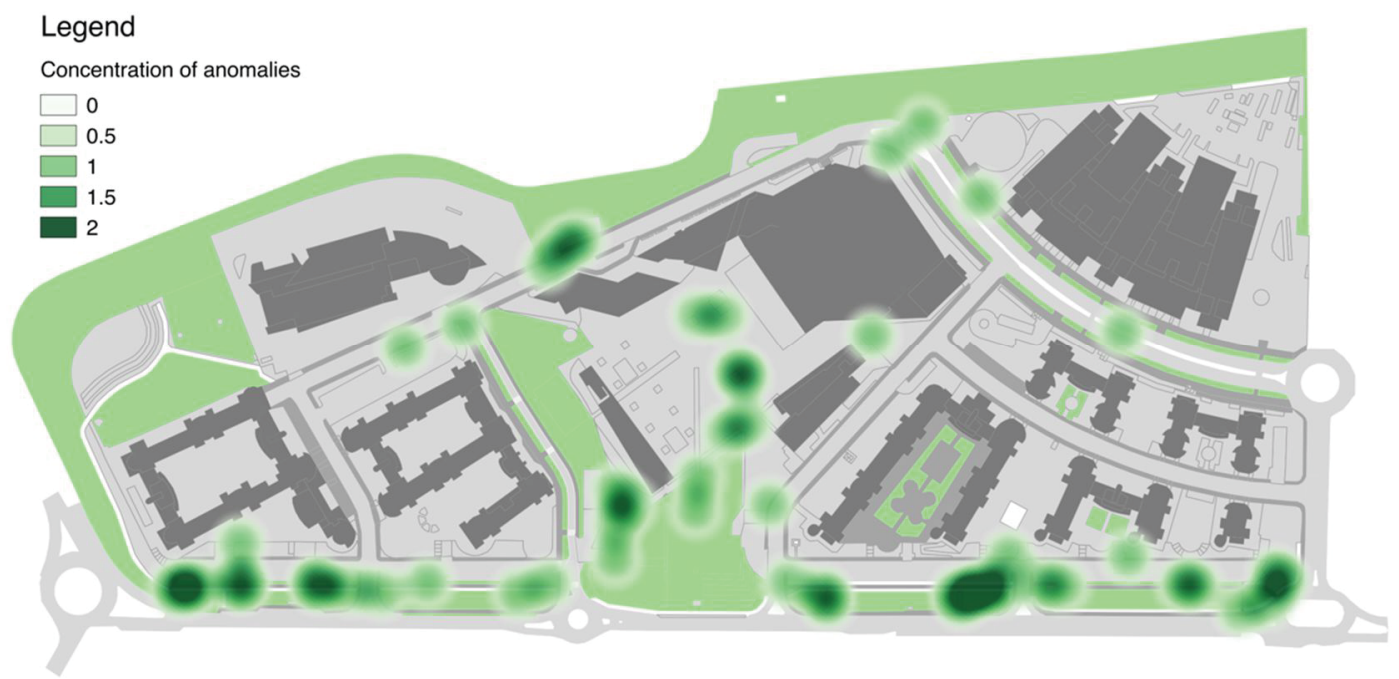

Figure 3: Concentration of anomalies in spaces related to BREEAM LE04 criterion (20m radius).

\section{DISCUSSION AND CONCLUSIONS}

The DIM, exploiting GIS and DBMS technologies, jointly with a mobile interface, furthers the speed up of UFM services' survey phase. Accordingly, approximatively in 
one week, it was possible to detect physical characteristics of Quartiere Affari Neighbourhood, gathering a great amount of information organised in sustainability reports concerning social and environmental assessment. Concerning social sustainability, it was demonstrated the possibility to assess safety issues of the neighbourhood, through a spatial analysis of concentration of anomalies. Despite not being exhaustive, this operation is crucial to setup a risk assessment and to prioritise maintenance interventions. In terms of environmental sustainability, it has been probed the possibility to extract thematic maps related to some criteria expressed by BREEAM Communities protocol. This opens to the possibility of exploitation of the DIM, for more comprehensive environmental assessment.

On the other hand, some further development of the research must be carried out. First of all, economic sustainability assessment, has not been implemented yet through the DIM, despite being a key issue to take into account in a comprehensive neighbourhood sustainability assessment.

Moreover, GIS, as mentioned before, allows the utilisation of machine and human readable file format: a feature fostering software interoperability. Recent studies on this topic, has demonstrated the possibility of tackle Building Information Modelling - BIM approach, exploiting COBie protocol (a subset of IFC) (MoJ, 2016), a dataset that could be possibly managed through a DBMS. Accordingly, it is suggested the possibility to integrate GIS and BIM, to achieve a broader assessment of the built environment.

\section{ACKNOWLEDGMENTS}

Authors would like to express their deepest gratitude to GEA S.r.l. and Consorzio Quartiere Affari for funding part of this research and for allowing us to test the model on site.

\section{REFERENCES}

Associazione Nazionale Costruttori Edili - ANCE (2014). Fascicolo di fabbricato. Dossier sulle leggi regionali. Direzione Legislazione Mercato Privato. Available at: http://www.anceaies.it/wp-content/uploads/2016/09/Fascicolo-di-fabbricato-cosahanno-previsto-le-Regioni-Allegato.pdf [Accessed Dec. 2016]

Building Research Establishment Environmental Assessment Method - BREEAM (2012). BREEAM Communities. Technical Manual. Available at: http://www.breeam.com/bre_PrintOutput/BREEAM_Communities_0_1.pdf [accessed Dec. 2016].

Comune di Milano. Direzione Centrale Sviluppo del Territorio (2014). Settore Sportello Unico per l'Edilizia (2014). D.C.C. 2 Ottobre 2014 n. 27. RE - Regolamento edilizio. Available at: http://mediagallery.comune.milano.it/cdm/objects/changeme:56114/datastreams/data Stream1040054932353380/content?pgpath=ist_it_contentlibrary/sa_sitecontent/segui _amministrazione/statuto_regolamenti/regolamenti/ef/edilizio, [Accessed Dec. 2016].

Dejaco, M.C., Maltese, S., Re Cecconi, F. Il fascicolo del fabbricato. 1st ed. Bologna: Maggioli Editore.

Ente Nazionale Italiano di Unificazione, (2011). UNI EN 15331. Criteri di progettazione, gestione e controllo dei servizi di manutenzione degli immobili. 
Ente Nazionale Italiano di Unificazione, (2012). UNI 11447. Servizi di facility management urbano - Linee guida per l'impostazione e la programmazione degli appalti.

Hoyt, L., Gopal-Agge, D. (2007). The Business Improvement District Model: A Balanced Review of Contemporary Debates. Geography Compass, 1/4, pp. 946-958.

Komeily, A., Srinivasan, R.S. (2015). A need for balanced approach to neighborhood sustainability assessments: A critical review and analysis. Sustainable Cities and Society, 18, pp. 32-43.

Maltese, S., Fradegrada, G., Moretti, N., Dejaco, M.C., Re Cecconi, F.(2016). GIS application in urban districts maintenance. $41^{\text {st }}$ IAHS World Congress: Sustainability and Innovation for the Future, 13-16 September 2016 Albufeira, Algarve, Portugal.

Maltese, S., Tagliabue, L.C., Re Cecconi, F., Pasini, D., Manfren, M., Ciribini, A.L.C. (2016). Sustainability Assessment through Green BIM for Environmental, Social and Economic Efficiency. International High-Performance Built Environment Conference - A Sustainable Built Environment Conference (SBE16), iHBE 2016.

Ministry of Justice - MoJ, Home Office, Crown Prosecution Service - CPS (2016). BIM2AIM quick start guide. Available at: ttps://download.4projects.com/document/publicfiles.aspx?RevisionID $\quad=20540548$ 3a20-4020-9f1e-362072511851 [accessed: Oct. 2016].

Shari, A., Murayama, A. (2014). Neighborhood sustainability assessment in action: Cross-evaluation of three assessment systems and cases from the US, the UK and Japan, Building and Environment, 72, pp. 243-258.

Shari, A., Murayama, A. (2015). Viability of using global standards for neighborhood sustainability assessment: Insights from a comparative case study, Journal of Environmental Planning and Management, Vol. 58, No. 1, pp. 1-23.

Sullivan, L., Ridin, Y., Buchanan, C. (2014). Neighbourhood Sustainability Frameworks A Literature Review. Frameworks for assessing the sustainability of the built environment with a focus at the neighbourhood level. UCL Working Paper Series Number: 001. Available at: https://www.ucl.ac.uk/usar/wps/USARWPS01-SullivanNeighbourhoods-PDF [Accessed in Dec. 2016].

Toso, F. (edited by) (2003). Certezze vs insicurezze. L'indagine cittadini / enti locali 2003. CRESME. Available at: http://radaris.it/p/Francesco/Toso/ [Accessed in 2015].

Wangel, J., Wallhagen, M., Malmqvist, T., Finnveden, G. (2016). Certification systems for sustainable neighbourhoods: What do they really certify? Environmental Impact Assessment Review, 56, pp. 200-213.

Yildiz, S., Yilmaz, M., Kivrak, S., Gültekin, A.B. (2016). Neighborhood Sustainability Assessment Tools and a Comparative Analysis of Five Different Assessment Tools. Planlama, 26(2), pp. 93-100.

Yoon, J. and Park, J. (2015). Comparative Analysis of Material Criteria in Neighborhood Sustainability Assessment Tools and Urban Design Guidelines: Cases of the UK, the US, Japan, and Korea. Sustainability, 7, pp. 14450-14487. 